\title{
PREDICTION OF NONLINEAR SYSTEM BY CHAOTIC MODULAR
}

\author{
Wang Chin-Tsan \\ Department of Mechanical and Electro-Mechanical Engineering, National I Lan University, I Lan, Taiwan, \\ ctwang@niu.edu.tw
}

Chen Ji-Cong

Department of Applied Mathematics, National University of Kaohsiung, Kaohsiung, Taiwan

Shaw Cheng-Kuang

Department of Mechanical and Aerospace Engineering, University of California, 420 Westwood Plaza, Los Angeles CA 90095, U.S.A.

Follow this and additional works at: https://jmstt.ntou.edu.tw/journal

Part of the Engineering Commons

\section{Recommended Citation}

Chin-Tsan, Wang; Ji-Cong, Chen; and Cheng-Kuang, Shaw (2010) "PREDICTION OF NONLINEAR SYSTEM BY CHAOTIC MODULAR," Journal of Marine Science and Technology. Vol. 18: Iss. 3, Article 3.

DOI: $10.51400 / 2709-6998.1879$

Available at: https://jmstt.ntou.edu.tw/journal/vol18/iss3/3

This Research Article is brought to you for free and open access by Journal of Marine Science and Technology. It has been accepted for inclusion in Journal of Marine Science and Technology by an authorized editor of Journal of Marine Science and Technology. 


\title{
PREDICTION OF NONLINEAR SYSTEM BY CHAOTIC MODULAR
}

\author{
Chin-Tsan Wang*, Ji-Cong Chen**, and Cheng-Kuang Shaw***
}

Key words: chaotic module, Lorenz attractor, Chua's circuit, chaotic wake flow.

\section{ABSTRACT}

Determining a suitable method of adequately predicting different nonlinear systems is necessary for instantaneous signal control. A chaotic modular found for realizing the prediction of signal control was applied to three different physical models: the Lorenz attractor, Chua's circuit, and chaotic wake flow. Testing results from the three cases show that the behaviors of the nonlinear systems are predicted for instant signal control successfully. This evidence confirms that the chaotic module found by the authors is very useful for instant signal control and can be utilized as a tool for instantaneous prediction of nonlinear systems.

\section{INTRODUCTION}

The chaos theory applied in this study is a relatively modern field developed to study the nonlinear physical system. Chaos can be seen as a complex non-periodic state which is sensitive to initial conditions and arises as a result of nonlinearity present in the system [10]. The chaotic scholar branch was first addressed by Lorenz [5], and the self-similar and fractal properties were found by Mandelbrot [6]. The photo image method had been applied by Sreenivasan [8] to study various kinds of flow field successfully [2-4, 7, 9]. Recently, the chaotic features embedded in the low frequency variations of the wake flow have been confirmed by the finding of chaotic attractor [11]. Hence, a chaotic module of a nonlinear dynamic system will be constructed by the topological transitive method and topological neighborhood method and further applied to discuss its prediction for a nonlinear system in this study.

Paper submitted 09/26/08; revised 03/31/09; accepted 06/11/09. Author for correspondence: Chin-Tsan Wang (e-mail: ctwang@niu.edu.tw).

*Department of Mechanical and Electro-Mechanical Engineering, National I Lan University, I Lan, Taiwan.

**Department of Applied Mathematics, National University of Kaohsiung, Kaohsiung, Taiwan.

***Department of Mechanical and Aerospace Engineering, University of California, 420 Westwood Plaza, Los Angeles CA 90095, U.S.A.

\section{TOPOLOGICAL TRANSITIVE INVARIABLE AND TOPOLOGICAL NEIGHBOR METHOD FOR CONSTRUCTION OF CHAOTIC MODULAR}

A chaotic module of a nonlinear system has been constructed by the topological transitive method and topological neighborhood method, originated from and addressed by the authors, will be further applied to study the prediction of three nonlinear systems for realizing its signal prediction scope. Hence, the deduction process of the chaotic modular will be addressed and the relevant results of such an approach are briefly summarized in this section.

Since the topological transitive invariable possess a feature of chaos, all relative positions between the topological points situated within a specific radius region (shown in the Fig. 1) do not change during the phase-space mapping procedure.

The geometric structure of a chaotic attractor is constructed by the trajectories of all topological points with the topological transitive invariable in the phase-space mapping process.

Based on topological neighbor theory, there are at least three neighboring points (white solid points in Fig. 2) close to each phase space state (a focal black point) and appearing in a parabolic curve. The relationship between each parabolic curve and its corresponding focal points for any phase-space state does not change because of the topological invariable feature. The historical phase trajectory of the chaotic attractor for any phase-space-time state-with $X(n-1), X(n)$ and $X(n+1)$ as examples - can be identified by a recall searching technique representing the local topological invariable geometrical structure.

Here, a polynomial function type is naturally chosen for determining the chaotic module because of its simple property.

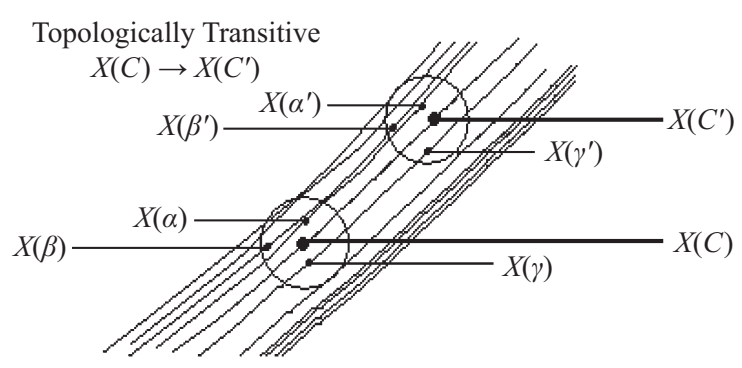

Fig. 1. Schematic diagram of topological transitive theory. 


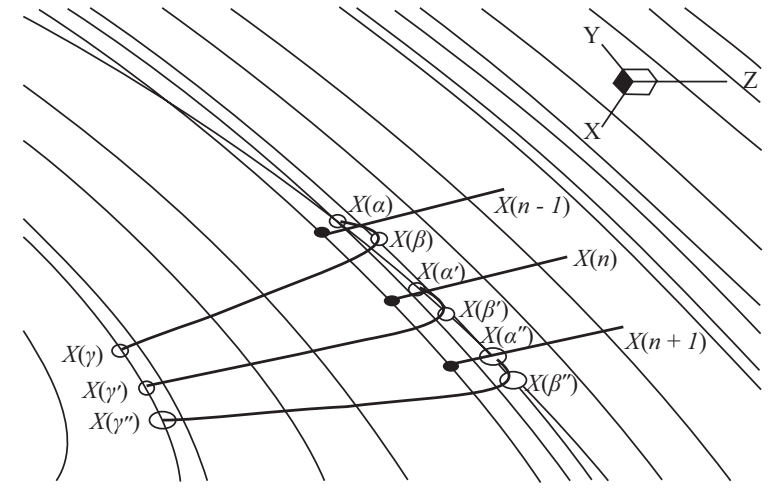

Fig. 2. Topological module line of Lorenz chaotic attractor.

A second order polynomial function of the chaotic modular with 41 coefficient numbers constructed will be applied with the intention to analyze the short-time prediction for the three nonlinear systems. Hence, Eq. (1) of the chaotic modular shall be rearranged to predict the subsequent state $X(n+1)$ of nonlinear system.

$$
\begin{aligned}
z(n+1)= & a_{1} z_{\alpha+1}+a_{2} z_{\beta+1}+a_{3} z_{\gamma+1}+a_{4} z_{n}+a_{5}+a_{6} x_{\alpha+1} y_{\alpha+1} \\
& +a_{7} y_{\alpha+1} z_{\alpha+1}+a_{8} z_{\alpha+1} x_{\alpha+1}+a_{9} x_{\beta+1} y_{\beta+1}+a_{10} y_{\beta+1} z_{\beta+1} \\
& +a_{11} z_{\beta+1} x_{\beta+1}+a_{12} x_{\gamma+1} y_{\gamma+1}+a_{13} y_{\gamma+1} z_{\gamma+1}+a_{14} z_{\gamma+1} x_{\gamma+1} \\
& +a_{15}\left(x_{\alpha+1}\right)^{2}+a_{16}\left(y_{\alpha+1}\right)^{2}+a_{17}\left(z_{\alpha+1}\right)^{2}+a_{18}\left(x_{\beta+1}\right)^{2} \\
& +a_{19}\left(y_{\beta+1}\right)^{2}+a_{20}\left(z_{\beta+1}\right)^{2}+a_{21}\left(x_{\gamma+1}\right)^{2}+a_{22}\left(y_{\gamma+1}\right)^{2} \\
& +a_{23}\left(z_{\gamma+1}\right)^{2}+a_{24} x_{\alpha+1}+a_{25} x_{\beta+1}+a_{26} x_{\gamma+1}+a_{27} y_{\alpha+1} \\
& +a_{28} y_{\beta+1}+a_{29} y_{\gamma+1}+a_{30} x_{n}+a_{31} y_{n}+a_{32} x_{n} y_{n} \\
& +a_{33} y_{n} z_{n}+a_{34} z_{n} x_{n}+a_{35}\left(x_{n}\right)^{2}+a_{36}\left(y_{n}\right)^{2}+a_{37}\left(z_{n}\right)^{2} \\
& +a_{38} x_{n-1}+a_{39} x_{n-1} y_{n-1}+a_{40} z_{n-1} x_{n-1}+a_{41}\left(x_{n-1}\right)^{2} \\
& =X(n+1)
\end{aligned}
$$

The coefficient value of chaotic modules for three nonlinear systems can further be obtained via the minimum mean square error method of (2).

$$
E_{n}=(X(n)-z(n))^{2}, \sum_{n} \frac{\partial E_{n}}{\partial a_{i}}=0 ; 3 \leq n \leq N, i=1,2, \ldots, 41
$$

Here, these constrains of (3) need to be considered for the prediction of instant signals.

$$
\alpha+1, \beta+1, \gamma+1 \leq n
$$

\section{A CHAOTIC MODULAR APPLIED TO PREDICTION OF NONLINEAR SYSTEM}

In this section three kinds of nonlinear systems, specifically the Lorenz attractor, Chua's circuit, and chaotic wake flow, will be selected to study its signal prediction scope.

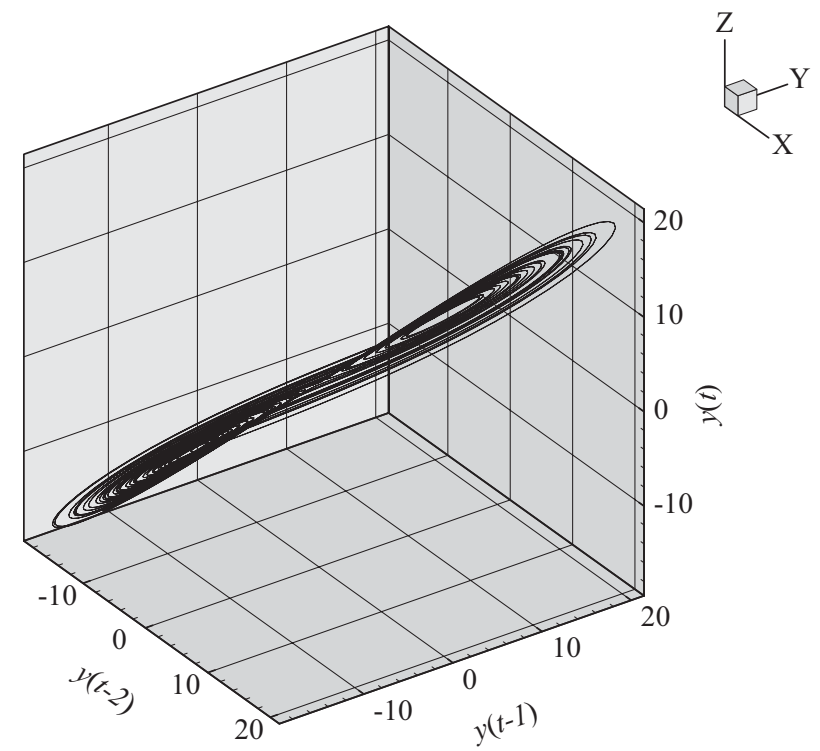

Fig. 3. The Lorenz attractor of the time-stagnation phase space for the temperature gradient solution.

\section{Lorenz Chaotic Attractor Model}

The differential equations of chaotic Rayleigh convection flow model were addressed by Lorenz [5] and shown in (4).

$$
\left\{\begin{array}{l}
x^{\prime}(t)=-10 x(t)+10 y(t) \\
y^{\prime}(t)=28 x(t)-y(t)-x(t) z(t) \\
z^{\prime}(t)=-\frac{8}{3} z(t)+x(t) y(t)
\end{array}\right.
$$

Here, the variable $x$ represents the strength of flow convection, the variable $y$ indicates the temperature in degrees of upstream flow and the variable $z$ is the temperature in degrees of downstream flow.

All the traces constructing the strange attractor structure were produced by (4) and situated in the elliptical sphere region of (5):

$$
14 x^{2}+5 y^{2}+5(z-56)^{2}=18000
$$

The three variables $x, y$ and $z$ can be deduced independently from (4) and the time-stagnation phase space for one independent variable can be reconstructed thusly. Figure 3 indicates the Lorenz strange attractor of time-stagnation phase space for the temperature gradients. The corresponding 41 coefficient numbers was obtained by (2) and shown in Table 1. The testing results of (1) for Lorenz attractor model on prediction conducted will be addressed in the next section.

\section{Chua's Circuit Model}

The Chua's circuit model shown in Fig. 4 and found by the Chua etc. [1] was one of chaotic systems in the electrical field 
Table 1. 41 coefficient numbers of topological modular line for three cases.

\begin{tabular}{|c|c|c|c|}
\hline $\begin{array}{c}\text { Coefficient } \\
\text { number }\end{array}$ & Lorenz attractor & Chua's circuit & Chaotic wake flow \\
\hline 1 & $2.370389526311 \mathrm{E}-03$ & $1.739763633104 \mathrm{E}-02$ & $2.215602687899 \mathrm{E}+00$ \\
\hline 2 & $2.465723299090 \mathrm{E}-03$ & $-2.979814406645 \mathrm{E}-03$ & $1.496333794929 \mathrm{E}+00$ \\
\hline 3 & 3.997324523415E-03 & $5.530156231291 \mathrm{E}-03$ & $1.163690236244 \mathrm{E}+00$ \\
\hline 4 & $3.643932400547 \mathrm{E}+00$ & $3.404919216580 \mathrm{E}+00$ & $3.847647302829 \mathrm{E}+00$ \\
\hline 5 & $-4.046578085123 \mathrm{E}-07$ & \begin{tabular}{|l}
$-2.891496513299 \mathrm{E}-05$ \\
\end{tabular} & $-1.098177288811 \mathrm{E}+00$ \\
\hline 6 & $1.515730352983 \mathrm{E}-02$ & \begin{tabular}{|l}
$-2.979731205781 \mathrm{E}-02$ \\
\end{tabular} & $-1.606127714764 \mathrm{E}+00$ \\
\hline 7 & $1.359787239260 \mathrm{E}-02$ & $6.091403200674 \mathrm{E}-01$ & $-1.237788653609 \mathrm{E}+00$ \\
\hline 8 & $-7.7733383444267 \mathrm{E}-03$ & $-2.323206760377 \mathrm{E}-01$ & $6.852802944147 \mathrm{E}-01$ \\
\hline 9 & $-2.128602849794 \mathrm{E}-02$ & $-4.643600159149 \mathrm{E}+00$ & $-5.974300793177 \mathrm{E}-01$ \\
\hline 10 & $-2.206892752643 \mathrm{E}-02$ & $-5.261349750548 \mathrm{E}+00$ & $-5.008537698792 \mathrm{E}-01$ \\
\hline 11 & $1.089695448559 \mathrm{E}-02$ & $2.632483517320 \mathrm{E}+00$ & $2.636023777752 \mathrm{E}-01$ \\
\hline 12 & $3.334799260583 \mathrm{E}-02$ & $6.513517648672 \mathrm{E}-01$ & $-1.189934409587 \mathrm{E}+00$ \\
\hline 13 & $3.016308720454 \mathrm{E}-02$ & $3.221819155130 \mathrm{E}-01$ & $-1.128247890033 \mathrm{E}+00$ \\
\hline 14 & $-1.563974888716 \mathrm{E}-02$ & $-2.157472391785 \mathrm{E}-01$ & $5.774582949865 \mathrm{E}-01$ \\
\hline 15 & $-4.160429816813 \mathrm{E}-03$ & $9.196684169106 \mathrm{E}-02$ & 4.711017113095E-01 \\
\hline 16 & $-1.346953843053 \mathrm{E}-02$ & -1.909087199411E-01 & $1.418338732002 \mathrm{E}+00$ \\
\hline 17 & $-3.359960985569 \mathrm{E}-03$ & $-2.604195950590 \mathrm{E}-01$ & $2.794213505565 \mathrm{E}-01$ \\
\hline 18 & $5.165880870369 \mathrm{E}-03$ & $1.139824251102 \mathrm{E}+00$ & $1.723034061318 \mathrm{E}-01$ \\
\hline 19 & $2.173442154709 \mathrm{E}-02$ & $4.662318279315 \mathrm{E}+00$ & $5.536568837153 \mathrm{E}-01$ \\
\hline 20 & $5.554117402056 \mathrm{E}-03$ & $1.476572874703 \mathrm{E}+00$ & $1.177386030926 \mathrm{E}-01$ \\
\hline 21 & $-8.762292869044 \mathrm{E}-03$ & $-2.120665233411 \mathrm{E}-01$ & $3.151074932714 \mathrm{E}-01$ \\
\hline 22 & $-3.193504142837 \mathrm{E}-02$ & $-5.076208283384 \mathrm{E}-01$ & $1.154949748153 \mathrm{E}+00$ \\
\hline 23 & $-7.178559266776 \mathrm{E}-03$ & $-5.103798313537 \mathrm{E}-02$ & $2.762756512792 \mathrm{E}-01$ \\
\hline 24 & $2.163141199641 \mathrm{E}-03$ & $2.159429064277 \mathrm{E}-03$ & $1.777599747491 \mathrm{E}+00$ \\
\hline 25 & $2.372267355596 \mathrm{E}-03$ & $-7.114401417362 \mathrm{E}-03$ & $1.629626002851 \mathrm{E}+00$ \\
\hline 26 & $3.984633047404 \mathrm{E}-03$ & $4.135026338174 \mathrm{E}-03$ & $1.065616888524 \mathrm{E}+00$ \\
\hline 27 & $-3.691022454964 \mathrm{E}-03$ & $-7.034008111945 \mathrm{E}-03$ & $-4.371255733060 \mathrm{E}+00$ \\
\hline 28 & $-4.357042292937 \mathrm{E}-03$ & $1.904569305089 \mathrm{E}-02$ & $1.046745284452 \mathrm{E}+00$ \\
\hline 29 & $-7.767110652408 \mathrm{E}-03$ & $-1.176908421809 \mathrm{E}-02$ & $-2.418362390883 \mathrm{E}+00$ \\
\hline 30 & $2.951392235832 \mathrm{E}+00$ & $2.891197128960 \mathrm{E}+00$ & $3.814554746577 \mathrm{E}+00$ \\
\hline 31 & $-4.942176588359 \mathrm{E}+00$ & $-4.626634111660 \mathrm{E}+00$ & $-5.685487397728 \mathrm{E}+00$ \\
\hline 32 & $-2.644981208143 \mathrm{E}-03$ & $1.723363443581 \mathrm{E}+00$ & $1.271289722443 \mathrm{E}+01$ \\
\hline 33 & $-1.697408286400 \mathrm{E}-01$ & $-1.438100366832 \mathrm{E}+00$ & $-4.958745709593 \mathrm{E}-01$ \\
\hline 34 & $7.561736285726 \mathrm{E}-02$ & $8.250177935493 \mathrm{E}-01$ & $-8.130983578413 \mathrm{E}-01$ \\
\hline 35 & \begin{tabular}{|l}
$-8.750576849512 \mathrm{E}-02$ \\
\end{tabular} & $-2.624760080089 \mathrm{E}+00$ & $-8.523049732929 \mathrm{E}+00$ \\
\hline 36 & $1.147803578650 \mathrm{E}-01$ & $5.171986045493 \mathrm{E}-01$ & $-4.323151648091 \mathrm{E}+00$ \\
\hline 37 & 4.728353611313E-02 & $3.957116345490 \mathrm{E}-01$ & $6.465684203172 \mathrm{E}-01$ \\
\hline 38 & $-6.547021710526 \mathrm{E}-01$ & $-7.083969180269 \mathrm{E}-01$ & $-9.803659059605 \mathrm{E}-01$ \\
\hline 39 & $1.012568286446 \mathrm{E}-01$ & $3.212650582348 \mathrm{E}+00$ & $5.069439020169 \mathrm{E}+00$ \\
\hline 40 & $-5.742273263842 \mathrm{E}-02$ & $-1.764046231659 \mathrm{E}+00$ & $-3.565878492622 \mathrm{E}+00$ \\
\hline 41 & $-2.160690765295 \mathrm{E}-02$ & $-8.275878889292 \mathrm{E}-01$ & $-7.323432173108 \mathrm{E}-01$ \\
\hline
\end{tabular}

and was taken into account in this study. The Chua's circuit model, which includes two capacitances $\left(C_{1}, C_{2}\right)$, one inductance $L$, one constant resistance $R$, and the nonlinear resistance $f\left(v_{1}\right)$ were obtained from (6).

The solution of Chua's circuit system of (7) for the variable $v_{2}$ was used for reconstructing the time-stagnation phase space concerning the attractor and is shown in Fig. 5. The 41 coefficient numbers of Chua's circuit system were found and are shown in Table 1. The predicting results for Chua's circuit system will be discussed in the next section.

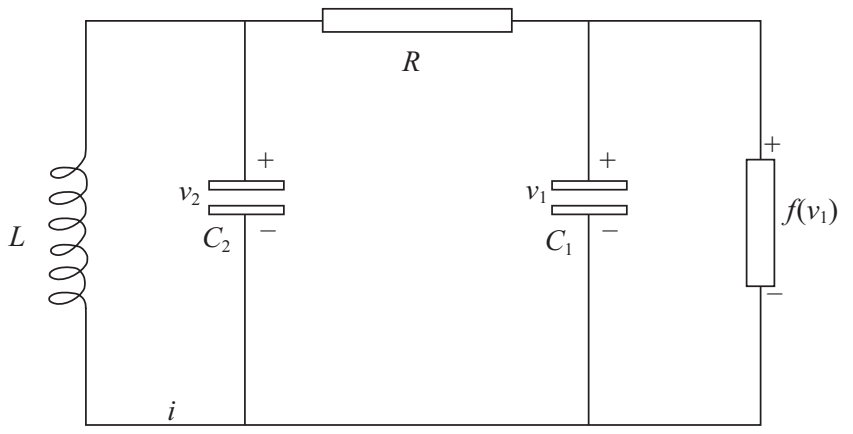

$G=1 / R, C_{1}=10.1 \mathrm{nF}, C_{2}=101 \mathrm{nF}, L=20.8 \mathrm{mH}, R=1420 \Omega$, $r=63.8 \Omega, G_{a}=-0.865 \mathrm{mS}, G_{a}=-0.519 \mathrm{mS}, B_{p}=1.85 \mathrm{~V}$

Fig. 4. Chua's circuit model [1].

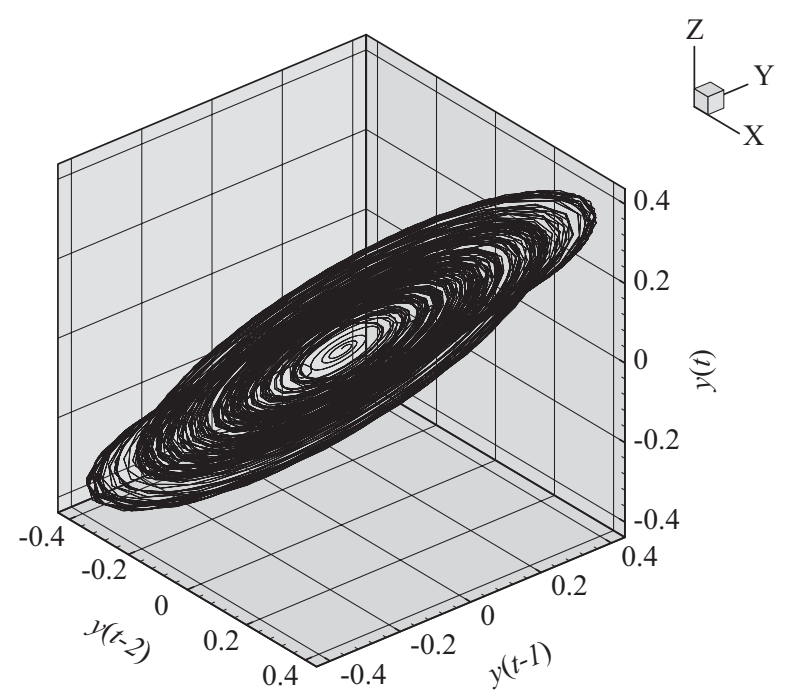

Fig. 5. Time-stagnation phase space of the capacitance voltage variance $v_{2}$ for attractor of Chua's circuit model.

$$
\begin{gathered}
f\left(v_{1}\right)=G_{b} v_{1}+0.5\left(G_{a}-G_{b}\right) \times\left(\left|v_{1}+B_{p}\right|-\left|v_{1}-B_{p}\right|\right) \\
\left\{\begin{array}{l}
\frac{d v_{1}}{d t}=\frac{1}{C_{1}}\left(G \times\left(v_{2}-v_{1}\right)-f\left(v_{1}\right)\right) \\
\frac{d v_{2}}{d t}=\frac{1}{C_{2}}\left(G \times\left(v_{1}-v_{2}\right)+i\right) \\
\frac{d i}{d t}=-\frac{v_{2}}{L}
\end{array}\right.
\end{gathered}
$$

\section{Chaotic Wake Flow}

The wake flow is a complex and unintelligible system. The existence of chaotic attractor embedded in wake flow and shown in Fig. 6 has been confirmed by Wang \& Chen [11]. The chaotic signals can be deduced from the original signals measured at $\mathrm{Re}=16500$ and filtered using the low-pass technique at a Strouhal cut-off frequency of $\mathrm{St}=0.138$. Finally, 


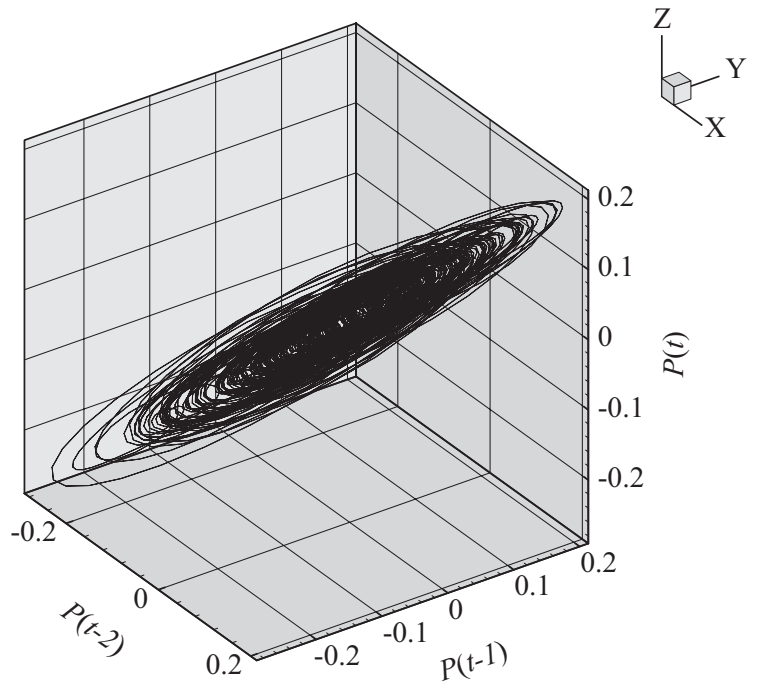

Fig. 6. Chaotic attractor is found and deduced from original base pressure signals of wake flow at $\mathrm{Re}=16500$ [11].

the chaotic wake flow prediction was obtained from (1). The corresponding 41 coefficient numbers are shown in Table 1 and is discussed below.

\section{TESTING RESULTS FOR THREE CASES OF NONLINEAR SYSTEMS}

For the topological transitive invariance theory and the inertial character of topological phase space, the predicting results were obtained from (1) of chaotic modular for three cases of nonlinear systems studied. The database of the 3250 samples was produced according to the exact solution for the Lorenz attractor and Chua's circuit models, respectively. Another test of the chaotic wake flow signals were obtained at $\mathrm{Re}=16500$. The preceding 500 samples of the database were adopted as a given state for predicting the oncoming state (unknown state). The 41 coefficient numbers of the chaotic modular for the three cases were collected and are shown in Table 1.

To determine the predicting precision of nonlinear system, two kinds of prediction methods, prediction of fixed initial value and prediction of float updating, were used in the study. The prediction of fixed initial value means that the database will not be renewed for oncoming stage. In contrast, the prediction of float updating indicates that the database needed will be renewed as database for oncoming stage. Here, it should be noted that numbers of the database needed to predict must be constrained to numbers of 500 samples.

Concerning the prediction results, Case (a) of Figs. 7-9 shows that the prediction of fixed initial value method can not adequately predict the dynamic behavior for all three cases. On the contrary, Case (b) of Figs. 7-9 executed by prediction of float updating method indicate that the difference between the real system and predicting data is smaller than the order of

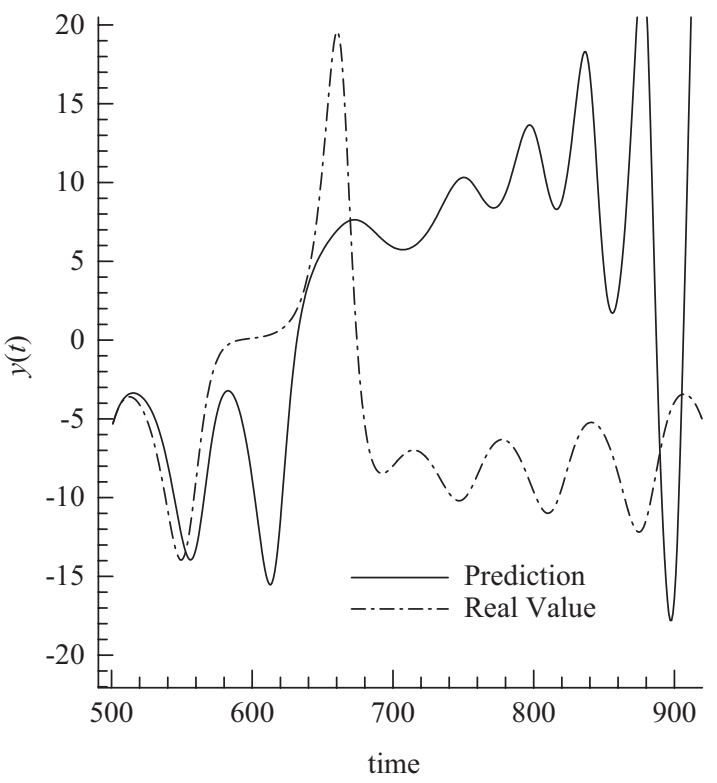

(a)

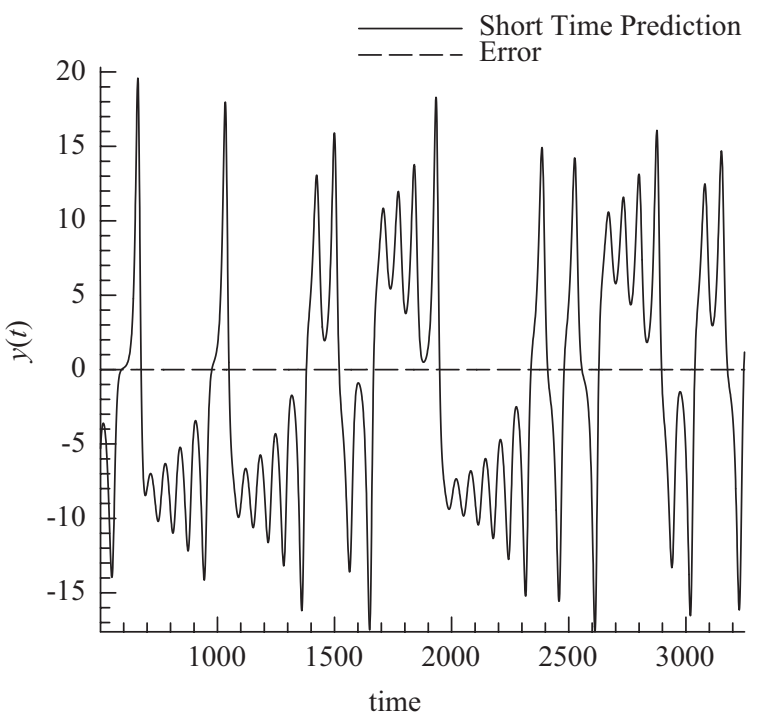

(b)

Fig. 7. Lorenz attractor: (a) prediction of fixed initial value (b) prediction of float updating.

$10^{-4}$ at any time state for the three cases. This evidence shows that the prediction of float updating method can predict the nonlinear system better than the prediction of fixed initial value method. The chaotic modular addressed by authors is suitable for the application of control for nonlinear systems and the prediction of float updating method should be seen as a useful tool for instant signal control.

\section{CONCLUSION}

A novel chaotic modular addressed by authors is used to predict the nonlinear system for the intention of determining 


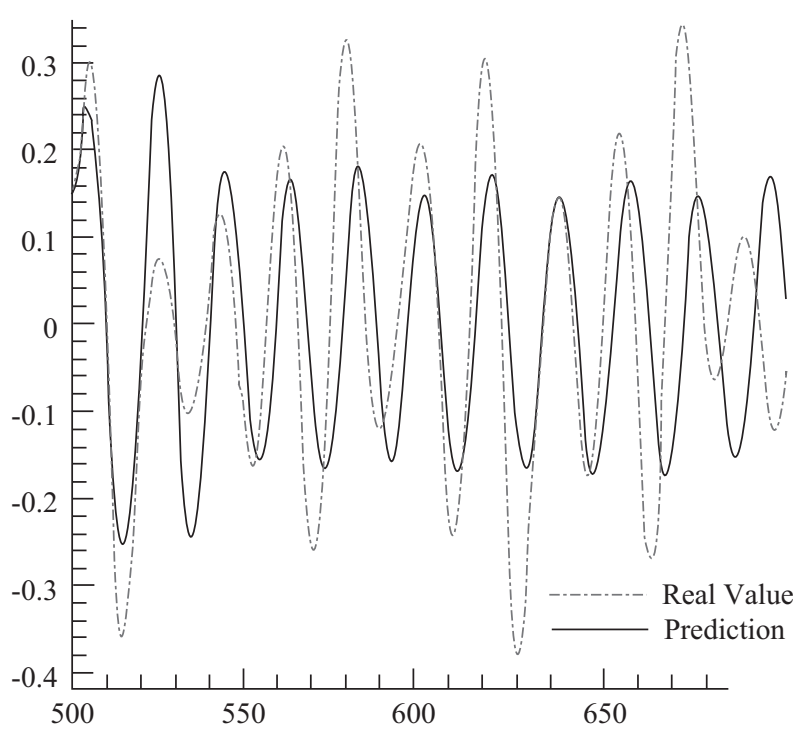

(a)

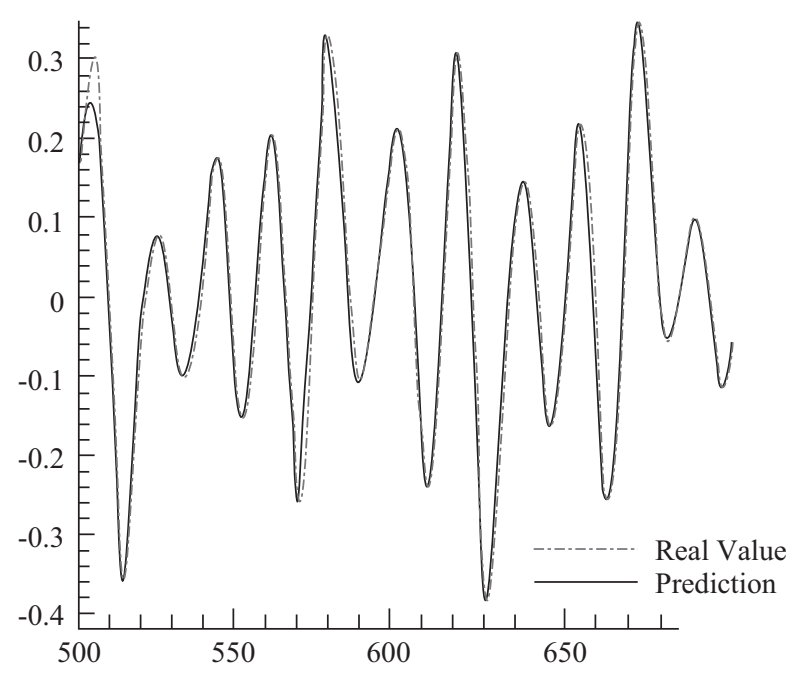

(b)

Fig. 8. Chua's attractor: (a) prediction of fixed initial value (b) prediction of float updating.

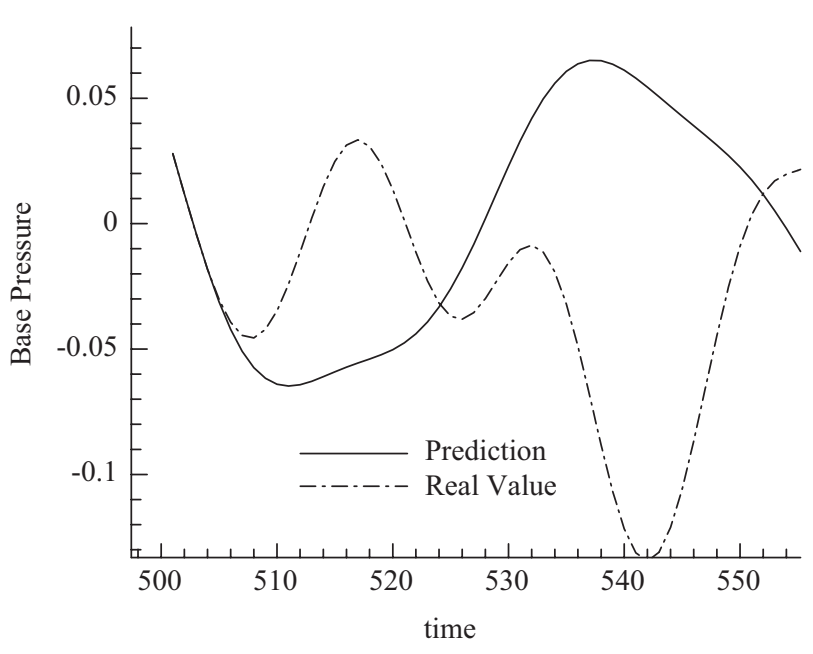

(a)

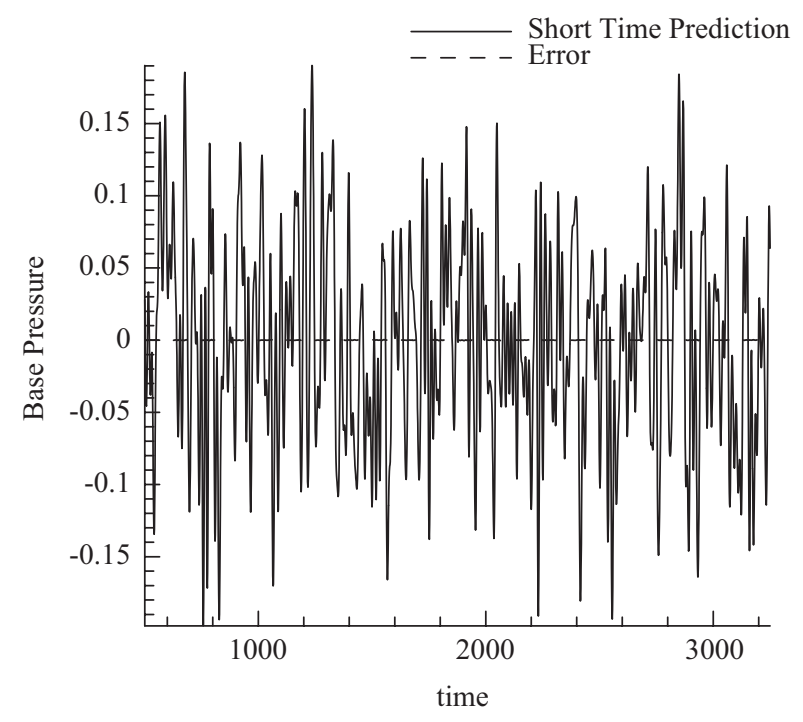

(b)

Fig. 9. Chaotic wake flow attractor: (a) prediction of fixed initial value (b) prediction of float updating.

its prediction ability. Three nonlinear systems consisting of the Lorenz attractor model, Chua's circuit model, and chaotic wake flow model, will be selected in name of three different fields. According to the prediction results, the prediction of float updating method can predict the nonlinear system better. The evidence shows that the chaotic modular addressed by authors is applicable to nonlinear systems and the prediction of float updating method can be used for extensive instantaneous signal control.

\section{REFERENCES}

1. Chua, L. O., Matsumoto, T., and Komuro, M., "The double scroll family,"
IEEE Transactions on Circuits and Systems, Vol. 37, pp. 885-902 (1986).

2. Frederiksen, R. D., Dahm, W. J. A., and Dowling, D. R., "Experimental assessment of fractal scale-similarity in turbulent flows. Part 1. Onedimensional intersections," Journal of Fluid Mechanic, Vol. 327, pp. 35-72 (1996).

3. Frederiksen, R. D., Dahm, W. J. A., and Dowling, D. R., "Experimental assessment of fractal scale similarity in turbulent flows. Part 4. Effects of Reynolds and Schmidt numbers," Journal of Fluid Mechanic, Vol. 377, pp. 169-187 (1998).

4. Lane-Serff, G. F., "Investigation of the fractal structure of jets and plumes," Journal of Fluid Mechanic, Vol. 249, pp. 521-534 (1993).

5. Lorenz, E. N., "Deterministic non-periodic flow," Journal of Atmospheric Science, Vol. 20, pp. 130-141 (1963).

6. Mandelbrot, B. B., "Note on the definition and stationarity of fractional Gaussian noise," Journal of Hydrology, Vol. 30, pp. 407-409 (1976). 
7. Prasad, R. R. and Sreenivasan, K. R., "Quantitative three-dimensional imaging and the structure of passive scalar fields in fully developed turbulent flow," Journal of Fluid Mechanics, Vol. 216, pp. 1-34 (1990).

8. Sreenivasan, K. R. and Meneveau, C., "The fractal facets of turbulence," Journal of Fluid Mechanics, Vol. 173, pp. 357-386 (1986).

9. Stolovitzky, G., Kailasnath, P., and Sreenivasan, K. R., "Refined similar- ity hypotheses for passive scalars mixed by turbulence," Journal of Fluid Mechanics, Vol. 297, pp. 275-291 (1995).

10. Swinney, H. L., "Observations of order and chaos in nonlinear systems," Physica D: Nonlinear Phenomena, Vol. 7, pp. 3-15 (1983).

11. Wang, C. T. and Chen, J. C., "Self-Similar analysis on vortex shedding process," Journal of Mechanics, Vol. 22, pp. 263-271 (2006). 